\title{
A discussion of the paper "Influence of surface charge on ingress of chloride ion in hardened pastes" by Y. Elakneswaran, T. Nawa, and K. Kurumisawa
}

\author{
Ueli Angst
}

Received: 10 October 2010/Accepted: 14 October 2010/Published online: 26 October 2010

(C) The Author(s) 2010. This article is published with open access at Springerlink.com

The authors of Ref. [1] are to be congratulated on their interesting contribution regarding the permselective character of cement paste. By experiments and a theoretical model they reached the conclusion that pore walls are negatively charged and thus attract positive ions in the double layer. Ionic transport through the pores can thus be expected to be affected by double layer effects, viz. deceleration of cations with respect to anions. These conclusions are in agreement with the findings of other authors [2-5]. There are, however, a few points that need to be considered in more detail. concentration of $C_{o}=0.01 \mathrm{~mol} / 1$ and the other of $C_{d}$ that ranged from 0.001 to $0.1 \mathrm{~mol} / \mathrm{l}$. Silver/silver chloride reference electrodes were introduced in both compartments by the use of salt bridges (saturated potassium chloride) and the potential difference between the two reference electrodes was measured for the various configurations regarding $C_{o}$ and $C_{d}$.

This potential difference is the sum of several contributions in the measurement circuit. Remember that diffusion potentials arise at boundaries where two solutions of different chemical composition are in contact [6]. The used setup contains the following interfaces:

sat. $\mathrm{KCl} / \mathrm{NaCl}\left(C_{o}\right) /$ pore solution in specimen $/ \mathrm{NaCl}\left(C_{d}\right) /$ sat. $\mathrm{KCl}$

$$
E_{1} \quad E_{2} \quad E_{3} \quad E_{4}
$$

The experimental methodology of Ref. [1] for determining diffusion potentials can be summarised as follows: Cement paste discs were cast and cured in saturated calcium hydroxide before being mounted in a typical diffusion-cell setup. Both compartments contained sodium chloride solutions, one at a

U. Angst ( $\bowtie)$

Department of Structural Engineering,

NTNU Norwegian University of Science and Technology, Richard Birkelandsvei 1A, 7491 Trondheim, Norway e-mail: ueli.angst@ntnu.no
Here, $E_{1}$ and $E_{4}$ are the liquid junction potentials across the interface of saturated $\mathrm{KCl}$ from the reference electrodes (salt bridges) and the solutions in the compartments; $E_{2}$ and $E_{3}$ are the diffusion potentials arising from the differences in chemical composition of compartment solutions and the pore solution inside the cement paste disc. In addition, an internal diffusion potential arises when a concentration gradient is present across the cement paste disc. In Ref. [1], the presence of $E_{2}$ and $E_{3}$ was recognised and referred to as Donnan potentials; the potential 
across the cement paste disc was termed $\Delta \Phi_{m}$ and simply called diffusion potential. The total voltage measured between the two reference electrode was termed membrane potential and denoted $\Delta \Phi$.

This terminology is confusing. Of course, all potentials arising in the circuit are diffusion potentials (and thus also the sum). However, permselective action is only expected within the pore system of the cement paste and thus the potential across the discand only there-should be referred to as membrane potential. The other contributions, $E_{1} \ldots E_{4}$ in Eq. 1, are consequences of the selected experimental setup and should be considered separately.

Please also note that immediately after installing the specimen in the diffusion cell setup, the composition of the pore solution within the disc is homogeneous. With time, however, as diffusion takes place, concentration profiles of the ionic species involved in the transport processes establish across the disc. As a result, $\Delta \Phi_{m}$ is initially zero, but assumes positive or negative values over time depending on the spatial distribution of all the involved ions. The total voltage along the measurement path, $\Delta \Phi$, on the other hand, might initially differ from zero since $E_{1} \ldots E_{4}$ are nonzero; at infinity, when all concentration gradients have levelled out, this potential difference will vanish. Please note the special case of an initially symmetric configuration $\left(C_{o}=C_{d}\right)$ where $E_{1} \ldots E_{4}$ cancel each other out and $\Delta \Phi$ becomes zero. The time dependence of measurements with such a setup has been experimentally shown in Refs. [7, 8].

To simplify matters, two stages will be considered in the following: a) the initial situation directly after immersing the cement paste discs, and b) an assumed intermediate stage where a linear sodium chloride concentration gradient has established across the disc (from $C_{o}$ to $C_{d}$ ). The total potential difference in the measurement circuit is:

$\Delta \Phi=E_{1}+E_{2}+\Delta \Phi_{m}+E_{3}+E_{4}$

As pointed out above, $\Delta \Phi_{m}$ is negligible in the first case. The individual diffusion potentials can be estimated by use of the Henderson equation [6, 9]. For the case of liquid junction potentials $E_{1}$ and $E_{4}$, this is straightforward, as the exact chemical composition of the solutions at the interfaces is known. For $E_{2}$ and $E_{3}$, the calculations can be based on the pore solution composition reported in Table 5 in Ref. [1] (from pore solution expression at age 28 day, w/c $=0.5$ ). As an example, $E_{2}$ and $E_{3}$ were calculated for the data given for ordinary Portland cement. The pore solution inside the discs was assumed to consist solely of sodium, potassium, calcium, and hydroxide ions (which were the most abundant species reported). The concentrations of the cations were taken from Table 5 in Ref. [1]; the hydroxide ion concentration was calculated from electroneutrality condition in the expressed pore solution. For the calculations, values for ionic mobility were taken from Ref. [10], temperature was set to $23^{\circ} \mathrm{C}$, and the saturation concentration of potassium chloride was $4.2 \mathrm{~mol} / \mathrm{l}$. A comment is here to be made on the $\mathrm{pH}$ values reported in Ref. [1] (Table 5): a pH of 10.24 for Portland cement paste cured in saturated calcium hydroxide for $28 \mathrm{~d}$ is rather low when compared with usual values ( $\mathrm{pH}>13$, see e.g. Ref. [11]). This is supported by the alkali metal concentrations measured in the expressed pore solutions in Ref. [1], which also imply that the $\mathrm{pH}$ is above 13. Perhaps, the expressed pore solution carbonated during handling and measurement.

Figure 1 depicts $\Delta \Phi$ in the setup ( $\times$ symbols) as estimated with the Henderson-equation approach and Eq. 2. It is apparent that the results are very similar for both stages (a) and (b). The reason for this is that the by far dominant diffusion potentials arise at the boundaries where the compartment solutions come into contact with the internal pore solution and large differences in $\mathrm{pH}$ are present. The effect of chloride concentration gradients is comparatively small. In other words: even if chloride concentration gradients are present, it is the differences in $\mathrm{pH}$ arising at various boundaries that largely determine the total voltage in the measurement circuit. For the same reason, when considering chloride concentration gradients within the disc, diffusion potentials become insignificantly low as long as the $\mathrm{pH}$ remains on a high level [12].

Also plotted in Fig. 1 is the data $(\Delta \Phi)$ reported by Elakneswaran et al. in Figs. 3-4 in Ref. [1]. It is striking, that the measured values are almost identical with those predicted in the present discussion. It can thus be concluded that the largest part of the observed voltages is likely to arise from solution boundary effects. The same or at least similar potentials would be measured in a setup consisting entirely of nonselective interfaces, e.g. porous ceramic frits instead 


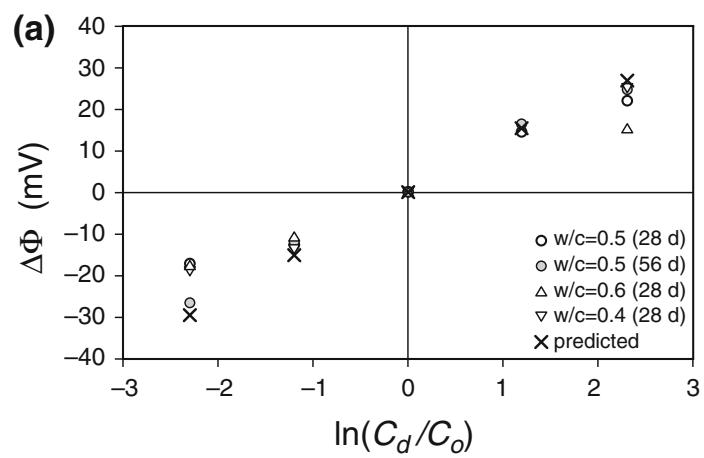

Fig. 1 Predicted total voltage in experimental setup ( $\times$ symbols): a directly after immersion, b when assuming a linear sodium chloride concentration gradient across the

of cement paste. With the compartment solutions selected in Ref. [1], only a minor fraction of $\Delta \Phi$ represents the very membrane potentials. The presented measurement results thus do not directly reflect permselective properties of the studied materials, but are to a large extent a consequence of the used experimental setup. To properly discuss the effect of permselective action of the studied pastes, corrections should be made to Figs. 3-5 in Ref. [1], i.e. $E_{1} \ldots E_{4}$ should be subtracted from $\Delta \Phi$. This, however, is problematic in the used setup as these contributions are considerably larger than the values of interest. Also the uncertainties associated with such corrections might be comparatively large and overshadow the membrane potential values.

Open Access This article is distributed under the terms of the Creative Commons Attribution Noncommercial License which permits any noncommercial use, distribution, and reproduction in any medium, provided the original author(s) and source are credited.

\section{References}

1. Elakneswaran Y, Nawa T, Kurumisawa K (2009) Influence of surface charge on ingress of chloride ion in hardened pastes. Mater Struct 42:83-93

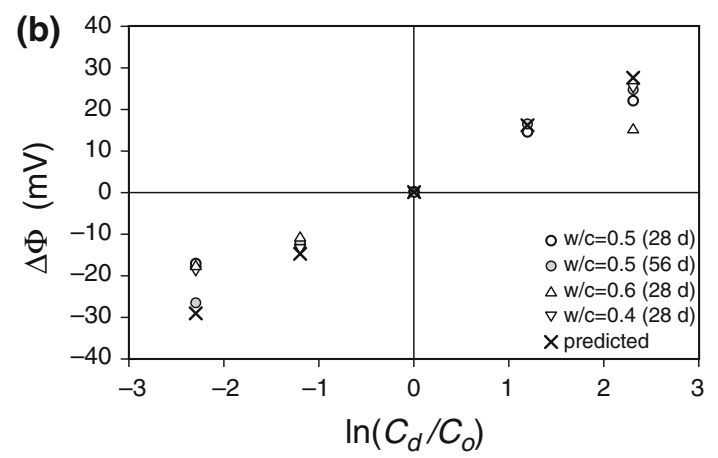

cement paste disc. For comparison, experimental data from Ref. [1] is also plotted (circles and triangles, Portland cement)

2. Goto S, Roy DM (1981) Diffusion of ions through hardened cement pastes. Cem Concr Res 11:751-757

3. Atkinson A, Nickerson AK (1984) The diffusion of ions through water-saturated cement. J Mater Sci 19:3068-3078

4. Chatterji S, Kawamura M (1992) Electrical double layer, ion transport and reactions in hardened cement paste. Cem Concr Res 22:774-782

5. Chatterji S (1994) Transportation of ions through cement based materials. Part 3: experimental evidence for the basic equations and some important deductions. Cem Concr Res 24:1229-1236

6. Bagotsky VS (2006) Fundamentals of electrochemistry, 2nd edn. The electrochemical society series. Wiley, New York

7. Zhang JZ, Buenfeld NR (1997) Presence and possible implications of a membrane potential in concrete exposed to chloride solution. Cem Concr Res 27:853-859

8. Zhang JZ, Buenfeld NR (2000) Measuring the membrane potential across cement-based materials. Mater Struct 33:492-498

9. Angst U, Vennesland $\varnothing$, Myrdal R (2009) Diffusion potentials as source of error in electrochemical measurements in concrete. Mater Struct 42:365-375

10. Bard AJ, Faulkner LR (2001) Electrochemical methods. Fundamentals and applications, 2nd edn. Wiley, New York

11. Elsener B, Zimmermann L, Böhni H (2003) Non destructive determination of the free chloride content in cement based materials. Mater Corros 54:440-446

12. Angst U, Vennesland $\varnothing$ (2009) Detecting critical chloride content in concrete using embedded ion selective electrodes-effect of liquid junction and membrane potentials. Mater Corros 60:638-643 